\title{
The origin of the 1500-year climate cycles in Holocene North-Atlantic records
}

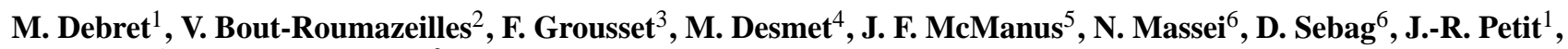 \\ Y. Copard ${ }^{6}$, and A. Trentesaux ${ }^{2}$ \\ ${ }^{1}$ Laboratoire de Glaciologie et de Géophysique de l'Environnement, UMR CNRS 5183, BP96, 38402, St Martin d'Hères, \\ France \\ ${ }^{2}$ PBDS Laboratoire, UMR 8110 CNRS, Université de Lille 1, 59655 Villeneuve d'Ascq, France \\ ${ }^{3}$ EPOC, UMR CNRS 5805, Université de Bordeaux I, Avenue des Facultés, 33405 Talence, France \\ ${ }^{4}$ EDYTEM Laboratoire, UMR 5204, Université de Savoie, CISM, Campus Scientifique 73376 Le Bourget du Lac Cedex, \\ France \\ ${ }^{5}$ Woods Hole Oceanographic Institution, Woods Hole, MA 02543, USA \\ ${ }^{6}$ Laboratoire de Morphodynamique Continentale et Côtière, UMR CNRS 6143, Département de Geologie, Université of \\ Rouen, 76821 Mont-Saint-Aignan Cedex, France
}

Received: 21 December 2006 - Published in Clim. Past Discuss.: 26 March 2007

Revised: 20 July 2007 - Accepted: 18 September 2007 - Published: 1 October 2007

\begin{abstract}
Since the first suggestion of 1500-year cycles in the advance and retreat of glaciers (Denton and Karlen, 1973), many studies have uncovered evidence of repeated climate oscillations of 2500, 1500, and 1000 years. During last glacial period, natural climate cycles of 1500 years appear to be persistent (Bond and Lotti, 1995) and remarkably regular (Mayewski et al., 1997; Rahmstorf, 2003), yet the origin of this pacing during the Holocene remains a mystery (Rahmstorf, 2003), making it one of the outstanding puzzles of climate variability. Solar variability is often considered likely to be responsible for such cyclicities, but the evidence for solar forcing is difficult to evaluate within available data series due to the shortcomings of conventional time-series analyses. However, the wavelets analysis method is appropriate when considering non-stationary variability. Here we show by the use of wavelets analysis that it is possible to distinguish solar forcing of 1000- and 2500- year oscillations from oceanic forcing of 1500 -year cycles. Using this method, the relative contribution of solar-related and oceanrelated climate influences can be distinguished throughout the $10000 \mathrm{yr}$ Holocene intervals since the last ice age. These results reveal that the 1500-year climate cycles are linked with the oceanic circulation and not with variations in solar output as previously argued (Bond et al., 2001). In this light, previously studied marine sediment (Bianchi and McCave, 1999; Chapman and Shackleton, 2000; Giraudeau et
\end{abstract}

Correspondence to: M. Debret

(debret@lgge.obs.ujf-grenoble.fr) al., 2000), ice core (O'Brien et al., 1995; Vonmoos et al., 2006) and dust records (Jackson et al., 2005) can be seen to contain the evidence of combined forcing mechanisms, whose relative influences varied during the course of the Holocene. Circum-Atlantic climate records cannot be explained exclusively by solar forcing, but require changes in ocean circulation, as suggested previously (Broecker et al., 2001; McManus et al., 1999).

\section{Introduction}

It was suggested, for both the late Glacial and the Holocene, a $1500 \mathrm{yr}$ variability of the climate (Bond et al., 1995, 1997, 2001). Initially associated with the so-called DansgaardOeschger oscillations (Dansgaard et al., 1993), this period seems to occur independently of the general glacialinterglacial climate changes. According to these results, the millennial-scale variability was attributed to the same forcing, ruling out any direct link with the ice-sheet oscillations. In North Atlantic as in other part of the world, many paleo-climatic records of the last 10000 years show a pattern of rapid climate oscillations with cyclicity around 1-2 kyrs. Since the pioneering studies of Gerard Bond on IRD from the North Atlantic Ocean (Bond et al., 1995, 1997, 2001), the 1500-year cycle during the Holocene was tentatively attributed to solar activity (Bond et al., 2001), to ocean current intensity variation (Bianchi and McCave, 1999), to tidal

Published by Copernicus Publications on behalf of the European Geosciences Union. 

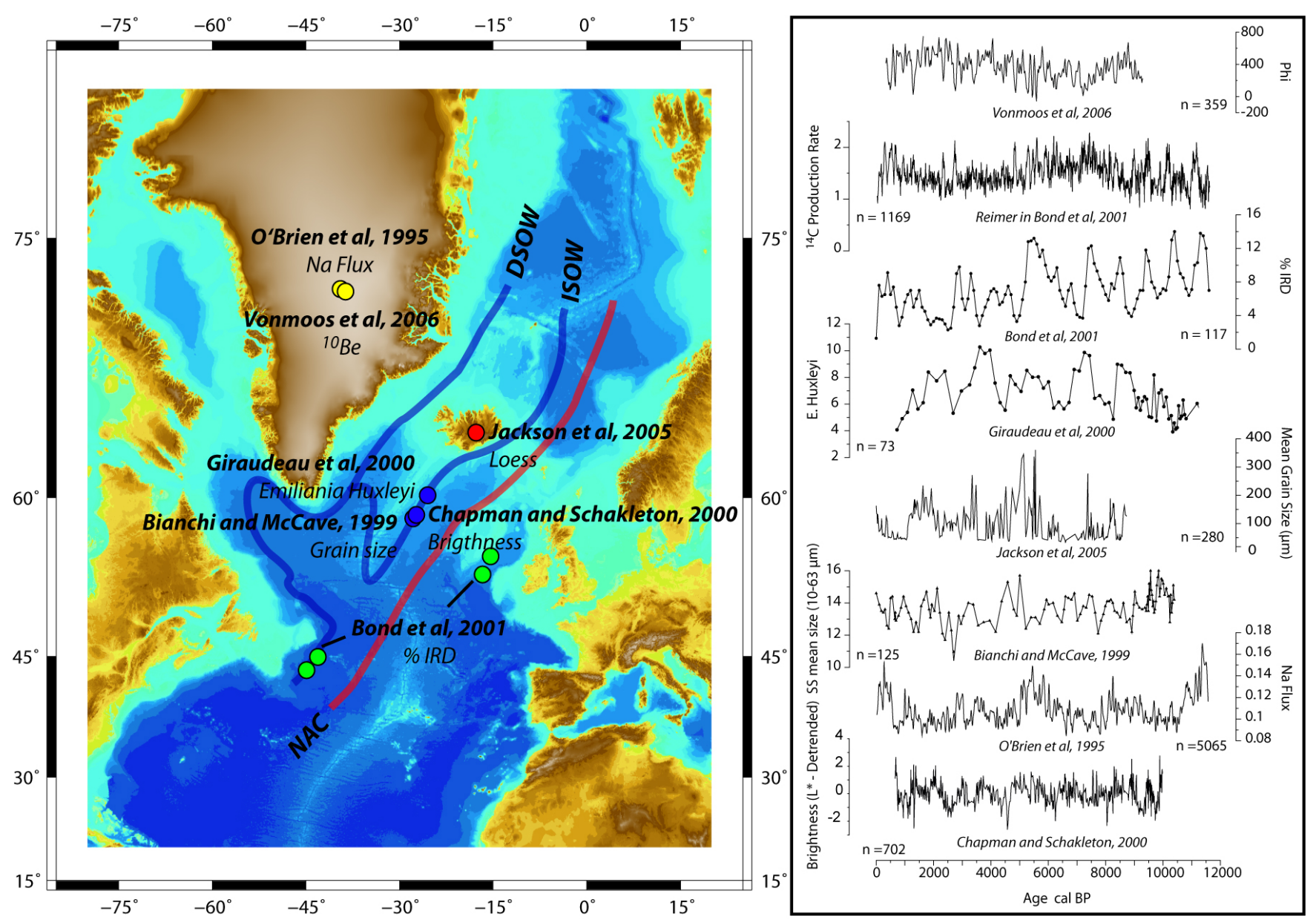

Fig. 1. Map of the North Atlantic region with location of the core sites along with the main patterns of the oceanic circulation (left), and the high resolution marine, continental and ice core records documenting the Holocene period (right). Left panel: the main North Atlantic Current (NAC) has two upper branches: one on the Eastern is the Iceland Scotland Overflow Water (ISOW) and the Denmark Strait Overflow Water (DSOW) on the West. Right panel, from top to bottom: Flux of ${ }^{14} \mathrm{C}$ (from P. Reimer in Bond et al., 2001), ${ }^{10} \mathrm{Be}$ coming from Grip ice core (Vonmoos et al., 2006). Ice rafted Debris (Bond et al., 2001), record of Emiliania Huxleyi concentration (from Giraudeau et al., 2000); Icelandic record of the mean grain size from loess deposits (Jackson et al., 2005); Marine record of sorted size grain (10-63 mm) record (from Bianchi and McCave, 1999); Greenland ice core record (GISP2) of sodium concentration (from O'Brien et al., 1995) and color of sediment (Chapman and Shackleton, 2000). The Ice Rafted Debris record from Bond et al., 2001 is a stack serie of 4 drillings (shown as green dot on the Map).

forcing (Berger and von Rad, 2002), to atmospheric processes linked to the North Atlantic Oscillation (NAO, Giraudeau et al., 2000) or to modifications of the geomagnetic field (St-Onge et al., 2003).

Up to now, classical Fourier spectral analysis remains the most common tool for studying the frequency pattern of a signal, although many alternative methods clearly improved the efficiency of Fourier analysis for variance density estimation (for instance, multi-taper methods).

Nevertheless, a thorough study of the Bond et al. (2001) time series clearly highlights the limits of Fourier spectral analysis. For instance, a simple Fourier transform (Blackmann-Tuckey, max entropy) provides 2 peaks corresponding to 1000-year and 2500-year cyclicities, while Bond et al. (2001) reported a quasiperiodic "1500-year oscillation"
(Fig. 2). The confidence limits shown on the figures were computed by testing the estimated power spectra against a background red noise spectrum (AR (1)) with a lag-1 autocorrelation of 0.11 . The background red noise spectrum was itself calculated by filtering noise from signal using eigenmode decomposition, noise being modelled thereafter using a first-order autoregressive spectrum procedure. As a matter of fact, the application of a 1000-year filter to the composite series of IRD does not provide very conclusive correlation during 0-5000 years, whereas the 1500-year Gaussian filter highlights a good correlation between filtered and raw data (Fig. 2) and conversely for the earlier part of the record. This provides a perfect example of the effect of instationarity in a signal. 

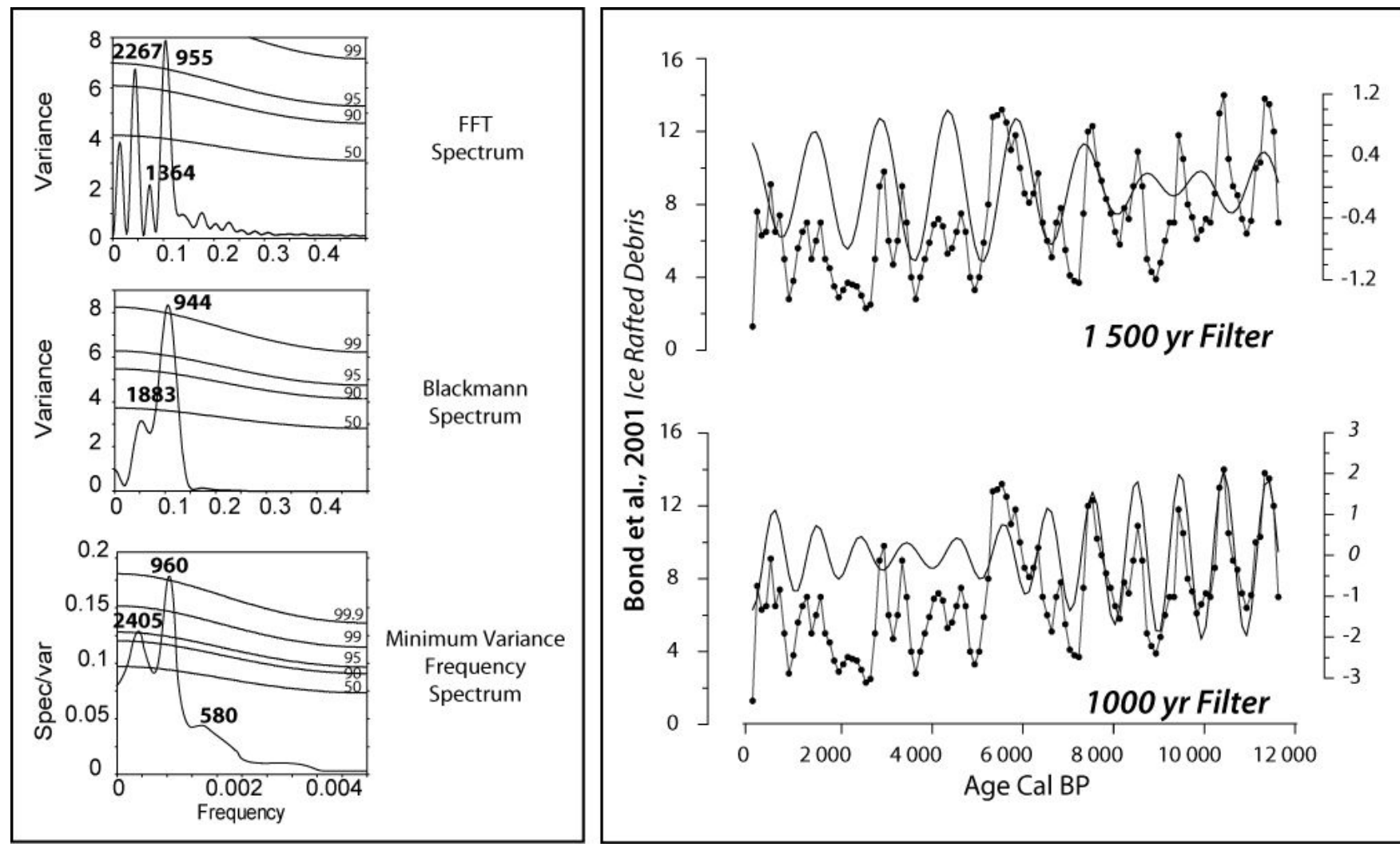

Fig. 2. Spectral analysis and filtered component of the stacked record from Bond et al. (2001). FFT highlights 2 major peaks in accordance with Blackmann-Tuckey and Maximum Entropie (left panel top). A small peak with a low energy around 1450-year appear only in FFT, however this periodicity is present between 1000 and 6000 years BP as shown by Gaussian filter applied on the series. On the other hand, the early Holocene period clearly displays 1000 years cycles. The bandwidth is 200 years for the Gaussian filters; we used e.g. 900-1100 years and 1400-1600 years, respectively.

This result demonstrates the limited ability of classical Fourier spectral analysis to detect a 1500 -year fluctuation that evolves through time. Such observations are typical of non-stationary processes, in which frequency content and statistical properties change through time. Wavelet analysis (WA) presents the advantage of describing non-stationarities, i.e. discontinuities, changes in frequency or magnitude (Torrence and Compo, 1998). Redundancy of the continuous wavelet transform is used to produce a time/frequency or time/scale mapping of power distribution, called the local wavelet spectrum (or scalogram). As a major advantage with respect to classical Fourier analysis, the local wavelet spectrum allows direct visualization of the changing statistical properties in stochastic processes with time.

WA performed on Bond et al. (2001) time series highlights 2 major cyclicities (up to $90 \%$ of confidence): 1000 and 2500 years (Fig. 3). The 2500-year cycle is continuous throughout the Holocene whereas the 1000-year cycle is absent during the Late Holocene (until 5000 years). This time-slice is characterized by an increase in spectral power at another period around 1500 years, reaching its maximum intensity at 3000 years but remains with a low confidence $(<50 \%)$. Bond et al. (2001) had compared their records with the ${ }^{14} \mathrm{C}$ produc- tion rate (Reimer in Bond et al., 2001) to justify the solar influence. We have processed the ${ }^{14} \mathrm{C}$ production rate (Reimer in Bond et al., 2001) and solar modulation function inferred from the ${ }^{10} \mathrm{Be}$ (Vonmoos et al., 2006) following the same protocol as the one used when processing the IRD data. WA reveals the same general feature for the ${ }^{14} \mathrm{C}$ production rate, ${ }^{10} \mathrm{Be}$ and IRD for the dominant periodicities with special emphasis on the attenuation of the 1000-year cycle during 5000-0 years period (Fig. 3). For the last millennia the problem is difficult to disentangle because only one cycle is concerned with a probable reappearance of 1000-yr cycle. This is likely in accordance with Little Ice Age well recognized in North Atlantic Area. These results corroborate the solar origin of the cycles at 1000 and 2500 years recorded in the IRD series. Nevertheless the two series show some discrepancies: a 1600-year cycle is recorded during the Holocene in the ${ }^{14} \mathrm{C}$ production rate excepted during $5000-0$ years when the 1500-year cycle of Bond'series is expressed (but with a low level of significance). Thus the occurrence of this 1500 year cycle in the IRD series records a forcing other than solar activity. Is it a pacing induced by a combination of cyclicities or a problem of proxy sensitivity to an other forcing factor? 

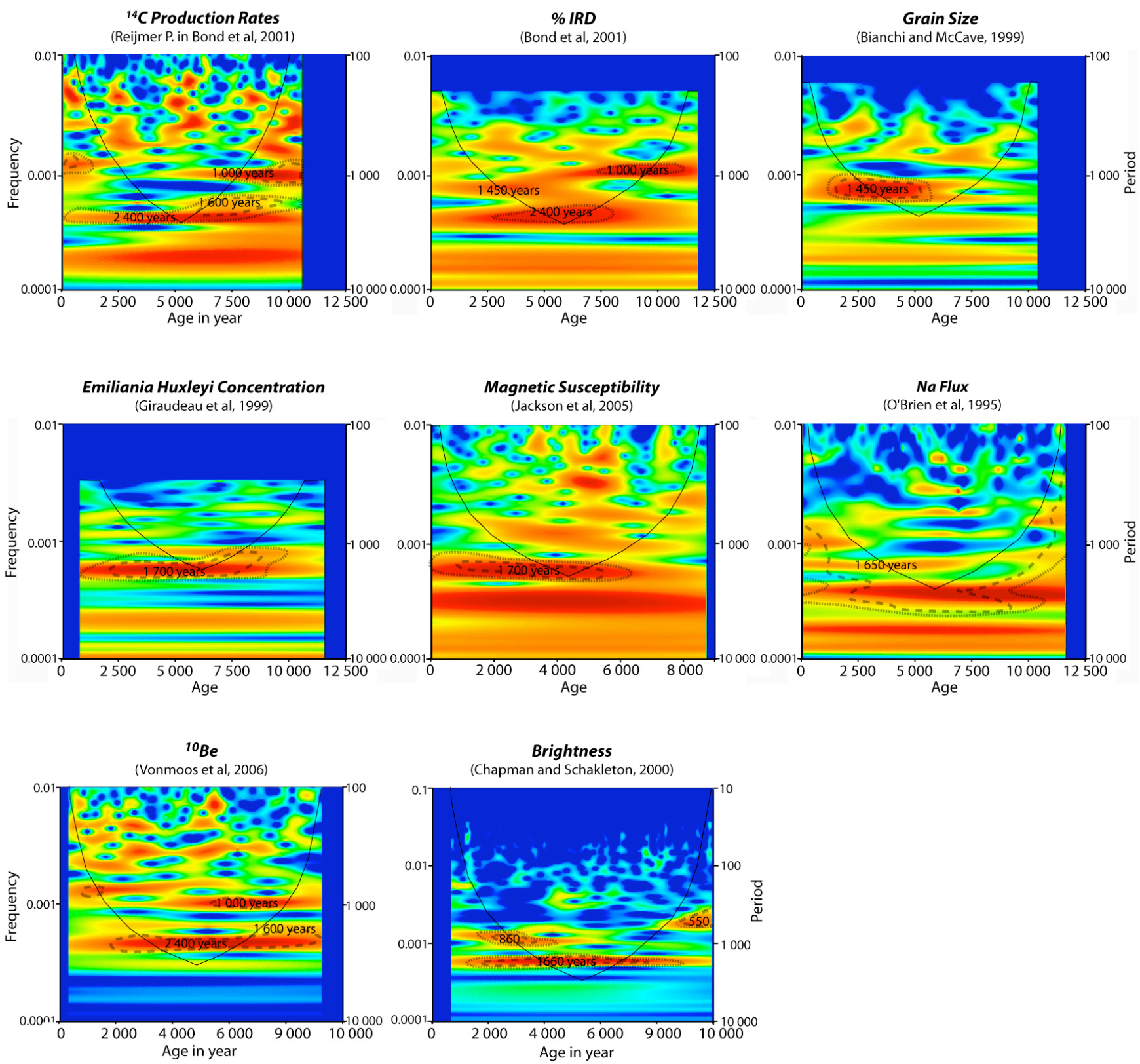

Fig. 3. Wavelet transform analysis of the marine, continental and ice core records of North Atlantic climate proxies over the Holocene period. Occurrence of the periods (labelled) with respect to the time is given by the bright yellow-red colours. Black line corresponds to cone of influence (see Methods paragraph). Horizontal band corresponding to periodicity higher than 3000 years are not meaningful. The confidence levels are indicated with the dot line: the fine one is $50 \%$ the larger is more than $95 \%$.

In this matter, WA were performed on some discriminating published records considered as well-dated data series of North Atlantic climate proxies, such as variations of the sediment grain-size to reconstruct the activity of deep-water masses. Also, we re-processed sortable silt grain-size data published by Bianchi and McCave (1999) on a sediment core situated off Iceland whose sedimentation is directly influenced by the activity of the "Iceland Scotland Overflow Water", ISOW, (Fig. 1), one of the main component of the ther- mohaline circulation. WA confirms the previously published results of FFT analysis (Bianchi and McCave, 1999) which evidenced a cyclicity around 1500 years. Moreover WA also highlights the maximum influence of this cyclicity during 5000-2000 years at this time the IRD displayed the 1500year cycle (Fig. 3). Chapman and Shackleton (2000), by the study of sediment color as a proxy of carbonate content, highlighted the same pattern with a frequency around 1660 years in the same core than Bianchi and McCave (1999). 
This is also confirmed with a 1700-years cycle in the Emiliania Huxleyi concentration record, a proxy of surface hydrology, in a core off Iceland (Giraudeau et al., 2005).

So we can propose that the IRD are not good proxies to track thermohaline activity in North Atlantic area. Indeed the oceanic forcing (1500 years) is found but only with a very low significance in the signal unlike solar forcing. Also, we can postulate that the IRD series, classically used as a reference of the climatic fluctuations during the Holocene, records at least one dominant forcing: solar activity for wavelengths at 1000- and 2500-year (up to $90 \%$ of the signal), and one minor: oceanic activity for the cyclicity at 1500 years characterising the late Holocene. According to the actual state of the art, this "double" forcing on the IRD signal can be mainly explained by the respective influence of solar activity on continental ice-sheets or calving, during the Early Holocene, and, for a lower level, of oceanic currents intensity strength on the geographical distribution of IRD in the North Atlantic Ocean during 5000-0 years cal BP. A question remains: what are the processes allowing to link solar cycle and IRD deposit in north Atlantic area? The dynamic of the ice sheet could be involved but implies a time response lag that is difficult to identificate. Perhaps could the sea ice and/or calving processes be a good contributor of this pattern however it remains still unclear.

In addition to analysis of several marine paleoclimatic proxies, the detailed Holocene variations of both ice-core and continental parameters were studied. The GISP 2 ice core from the summit of Greenland (Fig. 1) provides a precise and accurately-dated record of climatic changes during the Holocene. We looked at the evolution of sodium concentration in the ice because it is thought to represent the direct deposition of sea spray (O'Brien et al., 1995). WA of this signal reveals an unexpected result (Fig. 3): the variations of sodium shows an "oceanic forcing"-like cyclicity at 1600 years (1500-1700) during the late Holocene with maximum of intensity during the 5000-0 years cal BP. The striking feature of sodium flux in ice likely reflecting the cyclonic activity forced by ocean activity could be explained by considering the ocean-atmosphere coupling. Indeed in the North Atlantic Ocean the meridional overturning circulation obviously has a direct influence on sea-ice repartition subsequently affecting the synoptic atmospheric configuration in the North Atlantic area (O'Brien et al., 1995). As a result, the variations of the oceanic circulation near Iceland during the Holocene as recorded both by grain-size evolution (Bianchi and McCave, 1999) and Calcareous nannofossils abundance (Giraudeau et al., 2000) modify indirectly the atmospheric transfer of oceanic Na toward Greenland. However the very low confidence of this frequency with the signal of sodium flux in Greenland shows that an other proxy is needed. In order to constrain the atmospheric variability during the Holocene, a loess series from Iceland (Fig. 1, Jackson et al., 2005), the only dust record available, was analysed using WA. The results display a dominant 1700 years variabil-

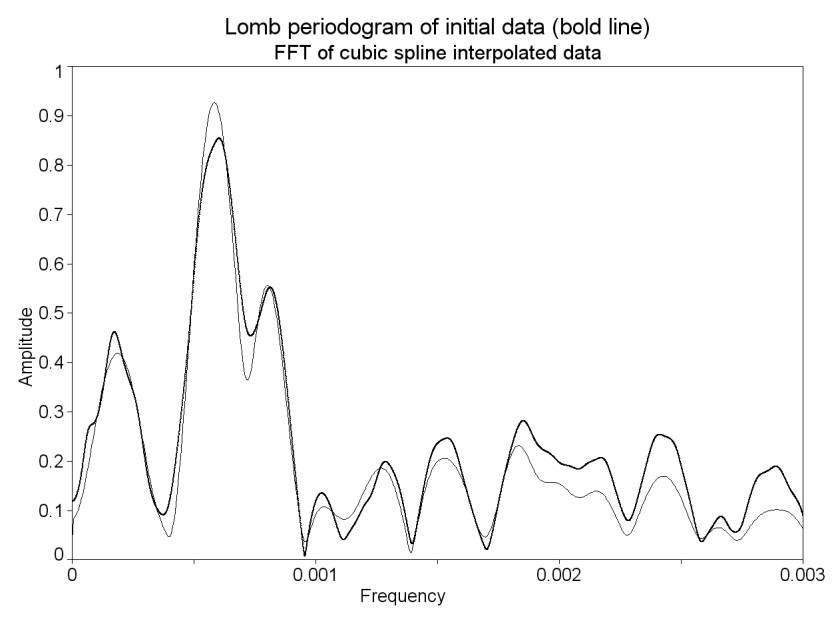

Fig. 4. Lomb periodogram of initial data (bold line) FFT of cubic spline interpolated data.

ity (Fig. 3) evidencing the influence of ocean activity on the overlying low-altitude atmospheric configuration confirming the oceanic pacing felt in Greenland ice core. The rather dispersive values obtained for the "so-called 1500-year cycle" through WA on the various data series analysed could result from discrepancies in their respective model-age (isotopic stratigraphy, $\mathrm{AMS}^{14} \mathrm{C}$, ice-core tuned).

\section{Conclusion}

By re-visiting well-known series from the North Atlantic Ocean, wavelet analysis reveals that the Holocene millennial variability is composed of at least three periodicities. Our results strongly suggest that two wavelengths are directly forced by solar activity (1000 and 2500-year cycles) whereas the third one (1600-year cycle, dominant during 5000-0 years) may correspond to oceanic internal forcing. Our results, based on a purely mathematical approach are not able to provide any additional explanation on the ori$\operatorname{gin}(\mathrm{s})$ of this oceanic variability, which may result from atmospheric water transport (Broecker et al., 2001) or a persistent internal salt oscillator (McManus et al., 1999) or perhaps an orbital modulation of the mechanisms driving millennialand centennial-scale climatic change through the Holocene as suggest by Turney et al. (2005). They nevertheless rule out the strictly external climate forcing due to variations in solar output through a linear process.

Although cyclicities of 1000 years and 2500 years are apparently broadly distributed over the whole climatic system (Nederbragt and Thurow, 2005) the global extension of the 1600-year cycle is much more controversial. Indeed the 1500 -year cycle is often evidenced within various series on the basis of a simple comparison with the mis-interpreted IRD reference dataseries, thus introducing a systematic bias in their conclusions. When submitted to our WA, these series 
display in fact cyclicities of 2500 and 1000 years instead of the expected 1500-year one. The circum-North Atlantic climate is particularly sensitive to changes in oceanic forcing due to changes in the strength of the meridional overturning circulation (Manabe and Stouffer, 2000; Alley et al., 1997; McManus et al., 2004). It remains to be seen whether this oceanic forcing extends globally, but the approach presented here provide a means to evaluate the respective influence of solar and oceanic forcing in high-resolution records from appropriate locations throughout the climatic system.

\section{Methods}

\subsection{Wavelet transforms}

The wavelet transform, contrary to the Fourier transform, is used to decompose a signal into a sum of small wave functions of a finite length that are highly localized in time, for different exploratory scales. By difference, Fourier transform aims to separate a signal into infinite-length oscillatory functions (sine waves) like, which results in a complete loss of time information as separated frequencies always apply to the entire length of the signal. Hence, instationary processes can not be described correctly using infinite complex exponentials, because of changes in frequency content across time. Wavelet transform is a band-pass filter which consists of convoluting the signal with scaled and translated forms of a highly time-localized wave function (the filter), the socalled "mother wavelet". The reference wavelet $\psi$, referred to as the "mother wavelet", comprises two parameters for time-frequency exploration, i.e. a scale parameter $(a)$ and a time-localization parameter $(b)$ so that:

$\psi_{a, b}(t)=\frac{1}{\sqrt{a}} \cdot \psi\left(\frac{t-b}{a}\right)$

Parameter $a$ produces "daughter wavelets" for investigation at different scale levels, while parameter $b$ allows translation of each daughter wavelet across time to detect changes in frequency content. The continuous wavelet transform of a signal $s(t)$, producing the wavelet spectrum, is defined as:

$S(a, b)=\int_{-\infty}^{+\infty} s(t) \cdot \frac{1}{\sqrt{a}} \cdot \psi\left(\frac{t-b}{a}\right) \cdot d t$

Time-frequency representation actually plots the wavelet power the time series. In practice, since the wavelet transform consists in applying a low-pass filter to a given time series, wavelet power is computed by fast Fourier transform (FFT), which makes easier the convolution of the time series by the wavelet filter (convolution in the time domain corresponds to a simple algebric product in the frequency domain). Once the Fourier transforms of the time series and the wavelet filter have been computed, the inverse Fourier transform of their product is calculated as follows:

$W_{n}(s)=\sum_{k=0}^{N-1} \hat{x}_{k} \cdot \hat{\psi}^{*}\left(s . \omega_{k}\right) e^{i \omega_{k} n \delta t}$

with $N$ : number of points in the time series, $s$ : scale of daughter wavelets, $n$ : time index, $k$ : frequency index, $\widehat{x}_{k}$ : Fourier transform of the initial time series $x_{n}, \widehat{\psi} *$ : complex conjugate of the Fourier transform of $\psi$ (wavelet filter), $\omega$ : frequency, $\delta t$ : time step. Finally, the wavelet power of the complex function $W_{n}(s)$ is defined as the square of the amplitude of the wavelet transform, that is, $\left|W_{n}(s)\right|^{2}$. The resulting plot of the wavelet power spectrum $\left|W_{n}(s)\right|^{2}$ is a contour map in which frequency, Fourier period or wavelet scale (y-axis), and power (z-axis) are plotted against time (x-axis). Several types of wavelet are available. In this study the Morlet wavelet (a gaussian-modulated sine wave) was chosen for continuous wavelet transform:

$\psi(\eta)=\pi^{-1 / 4} \cdot e^{i m \eta} \cdot e^{-\eta^{2} / 2}$

where $\eta$ is a dimensionless time parameter and $\mathrm{m}$ is the wavenumber that defines the basic resolution of the mother wavelet. A wavenumber of 10 was used, this choice offering a good trade-off between frequency and temporal resolution for the time series analyzed herein.

\subsection{Cone of influence}

To avoid edge effects and spectral leakage that are produced by the finit length of the time series, all series were zeropadded to twice the data length. However, zero-padding causes the lowest frequencies near the edges of the spectrum to be underestimated as more zeros enter the series. The area delineating this region is known as the cone of influence and marks those parts of the spectrum where energy bands are likely to be less powerful than they actually are because edge effects are becoming important.

\subsection{Statistical test}

For all local wavelet spectra, monte carlo simulation was used to assess the statistical significance of peaks. Background noise for each signal was estimated and separated using singular spectrum analysis. Autoregressive modelling was then used for each noise time series to determine the AR(1) stochastic process against which the initial time series was to be tested. $A R(1)$ background noise could be either white $(\operatorname{AR}(1)=0)$ or red noise $(\operatorname{AR}(1)>0)$.

\subsection{Unevenly time sampled records}

Blanks/gaps in the data were filled up/interpolated using a cubic spline interpolant (passes exactly through each data point). Although we did not use the weighted wavelet Ztransform algorithm, the cubic spline interpolation we used 
for handling unevenly-spaced data would not imply significant changes in the results of spectral/continuous wavelet analysis: for instance as shown in Fig. 4, a Lomb periodogram performed on the initial data of the most heterogeneously sampled series leads to the same results as a FFT of the interpolated time series (here interpolated to 4 times the length of the initial series).

Acknowledgements. Special thanks and respects to the memory of G. Bond: his innovative paper inspired this work.

We wish to thank M. Jackson, D. Oppo, J. Giraudeau, V. Peyaud, E. Chapron, M. Magny, P. J. Reimer, J. Beer for their valuable insight, avaibility and/or for having shared their data. The friendly review of N. McCave, P. Yiou, D. Raynaud and A. deVernal has been essential. We are very grateful to $\mathrm{A}$. Witt and the anonymous reviewer for very constructive criticisms and L. Beaufort, N. Otto, D.-D. Rousseau for their help during the review processing. This work is supported by ANR project: "Intégration des contraintes Paléoclimatiques pour réduire les Incertitudes sur l'évolution du Climat pendant les périodes Chaudes"- PICC (ANR-05-BLAN0312-02).

Edited by: L. Beaufort

\section{References}

Alley, R. B., Mayewski, P. A., Sower, T., Stuiver, M., Taylor, K. C., and Clark, P. U.: Holocene climate instability: a prominent, widespread event 8200 yrs ago, Geology, 25, 483-486, 1997.

Berger, W. H. and von Rad, U.: Decadal to millennial cyclicity in varves and turbidites from the Arabian Sea: Hypothesis of tidal origin, Global Planet. Change, 34, 313-325, 2002.

Bianchi, G. G. and McCave, N.: Holocene periodicity in North Atlantic climate and deep-ocean flow south of Iceland, Nature, 397 , 515-517, 1999.

Bond, G. G., Kromer, B., Beer, J., Muscheler, R., Evans, M., Showers, W., Hoffmann, S., Lotti-Bond, R., Hajdas, I., and Bonani, G.: Persistent Solar Influence on North Atlantic Climate During the Holocene, Science, 294, 2130-2136, 2001.

Bond, G., Showers, W., Cheseby, M., Lotti, R., Alsami, P., deMenocal, P., Priore, P., Cullen, H., Hajdas, I., and Bonani, G.: A pervasive millennial-scale cycle in North Atlantic Holocene glacial climates, Science, 278, 1257-1266, 1997.

Bond, G. and Lotti, R.: Iceberg discharges into the north Atlantic on millennial time scales during the last glaciation, Science, 267, 1005-1010, 1995.

Broecker, W., Sutherland, S., and Peng T.-H.: A possible 20thcentury slowdown of Southern ocean deep Water formation, Science, 286, 1132-1135, 2001.

Chapman, M. R. and Shackleton, N.: Evidence of 550-year and 1500-year cyclicities in North Atlantic circulation pattern during the Holocene, The Holocene, 10(3), 287-291, 2000.

Dansgaard, W., Johnsen, S. J., Clausen, H. B., Dahl-Jensen, D., Gundestrup, N. S., Hammer, C. U., Hvidberg, C. S., Steffensen, J. P., Sveinbjörnsdottir, A. E., Jouzel, J., and Bond, G.: Evidence for general instability of past climate from a $250-\mathrm{kyr}$ ice-core record, Nature, 364, 218-220, 1993.
Denton, G. H. and Karlén, W.: Holocene climatic variations - Their pattern and possible cause, Quat. Res., 3, 155-205, 1973.

Giraudeau, J., Cremer, M., Manthè, S., Labeyrie, L., and Bond, G.: Coccolith evidence for instabilities in surface circulation south of Iceland during Holocene times, Earth Planet. Sci. Lett., 179, 257-268, 2000.

Jackson, M. G., Oskarson, N, Trønnes, R. G., McManus, J. F., Oppo, D., Grönveld, K., Hart, S. R., and Sachs, J. P.: Holocene loess deposition in Iceland: Evidence for millennialscale atmosphere-ocean coupling in the North-Atlantic, Geology, 33, 509-512, 2005.

Manabe, S. and Stouffer, R. J.: Study of abrupt climate change by a coupled ocean-atmosphere model, Quat. Sci. Rev., 19, 285-299, 2000.

Mayewski, P. A., Meeker, L. D., Twickler, M. S., Whitlow, S., Yang, Q., Lyons, W. B., and Prentice, M.: Major features and forcing of high latitude nothern hemisphere atmospheric circulation using 110000 -year long glaciochemical series, J. Geophys. Res., 102, 26345-26366, 1997.

McManus, J. F., François, R., Gherardi, J.-M., Keigwin, L. D., and Brown-Leger, S.: Collapse and rapid resumption of Atlantic meridional circulation linked to deglacial climate changes, Nature, 428, 834-837, 2004.

McManus, J. F., Oppo, W. D., and Cullen, J. L.: A 0.5-millionyear record of millennial-scale climate variability in the North Atlantic, Science, 283, 971-974, 1999.

Nederbragt, A. J. and Thurow, J.: Geographic coherence of millennial-scale climate cycles during the Holocene, Pal3, 221, 313-324, 2005.

O'Brien, S. R., Mayewski, P. A., Meeker, L. D., Meese, D. A., Twickler, M. S., and Whitlow, S. L.: Complexity of Holocene climate as reconstructed from a Greenland ice core, Science, 270, 1962-1964, 1995.

Rahmstorf, S.: Timing of abrupt climate change: a precise clock, Geophys. Res. Lett., 30, 1510, doi:10.1029/1003GL017115, 2003.

Saint-Onge, G., Stoner, J. S., and Hillaire-Marcel, C.: Holocene paleomagnetic records from St. Lawrence Estuary, eastern Canada: Centennial- to millenial-scale geomagnétic modulation of cosmogenic isotopes, Earth Planet. Sci. Lett., 209, 113-130, 2003.

Stuiver, M., Reimer, P. J., Bard, E., Beck, J. W., Burr, G. S., Hughen, K. A., Kromer, B., McCormac, F. G., van der Plicht, J., and Spurk, M.: INTCAL98 radiocarbone age calibration, Radiocarbon, 40, 1041-1083, 1998.

Torrence, C. and Compo, G. P.: A practical guide to wavelet analysis, Bull. Am. Meteorol. Soc., 79, 61-78, 1998.

Turney, C., Baillie, M., Clemens, S., Brown, D., Palmer, J., Pilcher, J., Reimer, P., and Leuschner, H. H.: Testing solar forcing of pervasive Holocene climate cycles, J. Quat. Sci., 20, 511-518, 2005.

Vonmoos, M., Beer, J., and Muscheler, R.: Large variations in Holocene solar activity - constraints from ${ }^{10} \mathrm{Be}$ in the GRIP ice core, J. Geophys. Res., 111, A10105, doi:10.1029/2005JA011500, 2006. 